\title{
Bullshitting, Lying, And Indifference TOWARD TRUTH
}

\author{
ANDREAS STOKKE \\ Swedish Collegium for Advanced Study, Uppsala University \\ DON FALLIS \\ The University of Arizona
}

\begin{abstract}
This paper is about some of the ways in which people sometimes speak while being indifferent toward what they say. We argue that what Harry Frankfurt called 'bullshitting' is a mode of speech marked by indifference toward inquiry, the cooperative project of reaching truth in discourse. On this view bullshitting is characterized by indifference toward the project of advancing inquiry by making progress on specific subinquiries, represented by so-called questions under discussion. This account preserves the central insight of Frankfurt's influential analysis of bullshitting in seeing the characteristic of bullshitting as indifference toward truth and falsity. Yet we show that speaking with indifference toward truth is a wider phenomenon than the one Frankfurt identified. The account offered in this paper thereby agrees with various critics of Frankfurt who argue that bullshitting is compatible with not being indifferent toward the truth-value of one's assertions. Further, we argue that, while bullshitting and lying are not mutually exclusive, most lies are not instances of bullshitting. The account thereby avoids the problem that Frankfurt's view ultimately is insufficient to adequately distinguish bullshitting and lying.
\end{abstract}

\section{Introduction}

Many of our activities involve inquiry, that is, the pursuit of truth. Science, philosophy, history, criminal investigations, journalism, and even ordinary conversation about everyday matters all, at least paradigmatically, aim at discovering and sharing truths. Among our methods for inquiry, the most widespread is arguably that of acquiring information from the testimony of other people. This practice of gathering information from others depends for its success, at least

Contact: Andreas Stokke<andreas.stokke@filosofi.uu.se> and Don Fallis < fallis@email.arizona.edu> 
in part, on their sharing our concern for the pursuit of truth. We rely on others to make contributions that further the project of inquiry. However, people do not always share this concern. We sometimes have various non-alethic goals in conversation. We deceive each other, we mislead, we ignore evidence, we misrepresent.

The paradigmatic example of such non-truth-oriented speech is lying. But although lying has been studied extensively in recent philosophy (Carson 2006; 2010; Sorensen 2007; Fallis 2009; Saul 2012; Stokke 2013) little or no attention has been paid to other forms of non-alethic speech. A notable exception is Harry Frankfurt's well-known essay On Bullshit (2005). ${ }^{1}$ Frankfurt identified the phenomenon of bullshitting as a category of non-alethic speech distinct from lying. According to Frankfurt's influential analysis, bullshitting is a mode of speech characterized by a particular kind of indifference toward truth. In particular, for Frankfurt, the phenomenon of bullshitting is marked by the speaker being indifferent toward the truth or falsity of what she says. Moreover, Frankfurt sharply contrasted this kind of non-truth-oriented speech with lying. Whereas bullshitting is marked by indifference toward truth and falsity, Frankfurt held that the liar is "inescapably concerned with truth-values" (2005: 51). For this reason, Frankfurt saw bullshitting as more dangerous than lying in that it involves a greater disconnection from the pursuit of truth.

Frankfurt's analysis of bullshitting has been met with criticism (Cohen 2002; Kimbrough 2006; Carson 2010; Wreen 2013; Fallis 2015). In particular, Frankfurt's original suggestion that the mode of speech he was interested in centrally involves indifference toward truth and falsity has been challenged. It has been argued that people are often bullshitting even though they are not indifferent toward the truth-value of what they are saying.

In this paper we argue that indifference toward truth is a more diverse phenomenon than both Frankfurt and his critics have assumed. In particular, we argue that one may care about the truth-value of what one is saying, in the sense that Frankfurt's critics point to, and yet at the same time be indifferent toward truth and falsity in other ways. Motivated by this, we propose a conservative extension of Frankfurt's original account, which both answers the criticism that has been raised and further improves its explanatory power. We think Frankfurt was right that there is an interesting phenomenon that is characterized by indifference toward truth and falsity on the part of the speaker. But whereas Frankfurt originally claimed that the bullshitter lacks concern for the truth-value of her assertions per se, we suggest that bullshitting involves a slightly different kind of indifference toward truth and falsity.

1. The essay first appeared in Raritan, 6(2), in 1986. It was re-printed in Frankfurt (1988), and later as the monograph Frankfurt (2005). 
We argue that the bullshitter is characterized by a specific kind of indifference toward inquiry. As in the tradition from the work of Robert Stalnaker (1999a; 1984; 1999b; 2002), we take inquiry in discourse to be the cooperative project of incremental accumulation of true information with the aim of discovering how things are, or what the actual world is like. Following recent work by Craige Roberts $(2004 ; 2012)$, we distinguish inquiry in this overarching sense from particular subinquiries that discourse participants engage in, such as, for example, the project of finding out when the bus leaves, how cold it is outside, or whether someone has done their homework. As for Roberts, such subinquiries are represented by questions like When does the bus leave? or How cold is it outside? or Has John done his homework? A discourse is thereby seen as structured around a set of questions under discussion (henceforth, QUDs).

As a way of extending Frankfurt's original idea, we characterize bullshitting as a mode of speech marked by indifference toward contributing true or false answers to QUDs. The kind of indifference toward truth or falsity that characterizes the phenomenon of bullshitting is not indifference toward the truth-value of what one says, but indifference toward the effect that one's contributions have on the discourse.

This account accommodates the criticism of Frankfurt's original view in that it allows that someone can be bullshitting even though they care about the truthvalue of what they are asserting. On the account we will argue for, speakers may be indifferent toward making a true or a false contribution to a particular subinquiry, even if they are not indifferent toward the truth or falsity of their assertions.

One consequence of this view is that, contrary to what Frankfurt first proposed, some cases of bullshitting are also cases of lying. On our account, and as Frankfurt (2002) himself later acknowledged, the categories of lying and bullshitting overlap. In particular, we argue that when a speaker is bullshitting by asserting something she believes to be false, she is bullshitting by lying. But when a speaker tells a lie while being concerned with her assertion being a true or a false answer to a QUD, she is not bullshitting on our view. Since the latter type of lie is by far the most common, our proposal has the consequence that most cases of lying are not instances of bullshitting.

However, as we will argue, Frankfurt's (2002) remarks on the intersection between bullshitting and lying are ultimately insufficient to adequately distinguish the two phenomena. By contrast, the QUD framework provides a straightforward way of allowing that the two categories overlap, while preserving what was right about Frankfurt's original view of the two phenomena as largely distinct.

Moreover, our account helps explain why bullshitting is such a dangerous "enemy of truth" (Frankfurt 2005: 61). Our view captures the fact that, as inquirers, we do not just care about the truth of individual propositions, and we do 
not evaluate the value of someone's epistemic state by adding up the number of true beliefs she has. We care about truth because we are engaged in subinquiries, because we are trying to answer QUDs.

In Section 2 we consider the phenomenon of bullshitting while caring about the truth-value of what one says, and we argue that this phenomenon involves different ways of being indifferent toward truth and falsity. Section 3 spells out our account, and we show that it preserves what was right about Frankfurt's initial proposal while answering the main criticism of it. In Section 4 we show how our account captures two further phenomena involving evasive bullshitting and the possibility of advancing inquiry by bullshitting. Finally, Section 5 spells out the consequences of our account for the relation between bullshitting and lying.

\section{Caring and Not Caring about Truth}

\section{I. Frankfurt on Indifference toward Truth and Falsity}

Frankfurt identified bullshitting as a mode of speech characterized by indifference toward truth and falsity. As illustrated by Frankfurt's discussion, speaking with indifference toward truth and falsity is common in many areas of contemporary culture, including advertising and politics. But even outside such areas of public discourse, people sometimes engage in talk characterized by this kind of indifference. Even in our private lives, we are familiar with the fact that people sometimes say things without caring whether what they say is true or false. There are many reasons people might do so. They may be trying to present themselves in a certain way or they might think (perhaps correctly) that the situation calls for certain things to be said regardless of their truth or falsity, and there might be other reasons. We will look at some of these in what follows.

One of Frankfurt's main examples of bullshitting was a certain kind of political speech making, as in the following passage:

\section{$4^{\text {th }}$ of July Orator}

Consider a Fourth of July orator who goes on bombastically about "our great and blessed country, whose Founding Fathers under divine guidance created a new beginning for mankind." (Frankfurt 2005: 16)

According to Frankfurt, the central characteristic of this kind of talk is that the speaker is indifferent toward the truth or falsity of what she says. In an often quoted passage Frankfurt describes the bullshitter as follows: 
Her statement is grounded neither in a belief that it is true nor, as a lie must be, in a belief that it is not true. It is just this lack of connection to a concern with truth - this indifference to how things really are - that I regard as of the essence of bullshit. (Frankfurt 2005: 33-34)

So, for Frankfurt, the key characteristic of the kind of talk he wants to identify as bullshitting is indifference toward whether what one says is true or false.

\subsection{Bullshitting while Caring about Truth}

Against Frankfurt's original idea, it has been suggested that bullshitting does not always involve indifference toward truth. In particular, a number of philosophers have argued that people are sometimes bullshitting even though they care about the truth or falsity of what they say (e.g., Cohen 2002; Kimbrough 2006: 12-13; Carson 2010: 62-63; Wreen 2013: 110; Fallis 2015).

Here is an example that Thomas Carson (2010) gives:

\section{Careful Exam Taker}

A student who gives a bullshit answer to a question in an exam might be concerned with the truth of what [s] he says. Suppose that she knows that the teacher will bend over backwards to give her partial credit if he thinks that she may have misunderstood the question, but she also knows that if the things she writes are false she will be marked down. In that case, she will be very careful to write only things that are true and accurate, although she knows that what she writes is not an answer to the question. (Carson 2010: 62)

The bullshitting student cares about the truth of what she says in the sense that she cares about saying true things, while she is not particularly concerned with what they are. Even though the student is concerned with making true statements, she is not trying to answer the exam questions correctly, since she knows that she is unable to do so.

It is not difficult to find more examples of the same type of attitude toward one's speech. Consider, for instance, the case of filibusters. Some filibusters parallel the Careful Exam Taker's strategy of bullshitting while being careful to only say true things. Roy Sorensen (2011) cites an instance from ancient Roman history: 


\section{Cato}

When opposing Caesar, the Roman senator, Cato the Younger, delayed votes with rambling speeches that violated the maxims of quantity ('Say only as much as needed'), relation ('Be relevant') and manner ('Be clear'). As a Stoic, Cato condemned lying. This principle was not violated by him bullshitting until dusk (the time at which the Senate was obliged to conclude its business). (Sorensen 2011: 406)

As in the Careful Exam Taker case, Cato was careful to only say things he believed to be true, thereby avoiding lying. Yet at the same time his filibustering tactic involved not being concerned with the particular things he said, as long as they were true. Like the student in Carson's example, Cato was merely concerned with the truth of what he said in one sense, while he was indifferent toward truth in another sense. While Cato was concerned with saying true things, he was not particularly interested in what they were.

As these examples suggest, one way in which one can be concerned with the truth of what one says is to have a general concern that is not directed at particular propositions. People sometimes try to make sure that their utterances are true, even if they are not concerned with the truth-value of any particular propositions. We think this kind of speech is usefully characterized as bullshitting while caring about the truth of what one says.

A different kind of example has been suggested by Jonathan Webber (2013). He writes,

one can communicate bullshit conversational implicatures. If one's intention is to instill in one's audience a particular belief that one neither believes nor disbelieves, then one can pursue this aim by making assertions that carry the target proposition as a conversational implicature. One could implicate it by asserting only truths, which might be a wise strategy for politicians or advertisers. (Webber 2013: 655-656)

As Webber points out, another way of bullshitting while caring about saying true things is to say something one believes to be true in order to conversationally implicate something the truth-value of which one does not care about. As we might say, these are cases of bullshit implicatures.

For example, imagine an advertisement for a toothpaste saying, 'Used by dentists!' That the toothpaste is used by dentists may be true, and the advertiser might care about its being true, perhaps for fear of being sued should the ad say something false. At the same time the slogan may be intended to implicate that the toothpaste is good, or perhaps that it is better than toothpastes not used by 
dentists. Yet the advertiser might not care whether such implicatures are true or false.

The examples considered above are all cases in which someone cares about truth in the sense of having a goal of saying true rather than false things. We want to point out another way in which one might care about the truth of what one says. This is the sense in which one might care about the truth of one or more specific propositions. This kind of concern for the truth is also compatible with bullshitting, that is, with being indifferent toward truth and falsity in a different sense.

Consider the following story:

\section{Wishful Thinker}

Jack and Julia are going to Chicago. They have tickets to a Cubs game, and being a big Cubs fan, Julia hopes the game will not be rained out. A few days before their departure, they are talking about their trip. Jack says, 'I'm really looking forward to that Cubs game. I hope it won't rain.' Julia replies with a confident air, 'This time of year, it's always dry in Chicago.' But she has no evidence about the weather in Chicago, and she has no idea whether it's likely to rain or not.

There is a clear sense in which Julia is not indifferent toward the truth-value of what she says. But unlike the speakers in the previous examples, Julia's goal is not simply to say something true, while being less concerned about the particular proposition she utters. Rather, she cares particularly about the truth of the proposition she utters. She is not indifferent to whether it is always dry in Chicago at that time of year. She wants it to be true that it is always dry in Chicago at that time of year. Or, if one prefers, she hopes or wishes that it is. Even so, Julia is speaking with indifference toward truth in another sense. In particular, as we will argue, speakers like Julia are characterized by a particular kind of indifference toward inquiry. Hence, we think that Julia should be characterized as bullshitting.

Some might think that Julia is not making a genuine assertion and therefore cannot correctly be described as bullshitting. It might be said that Julia is more like the person along the race course who is simply shouting out encouragement ('You can do it!'). However, we think there is a reading of the case on which Julia is not simply trying to invigorate the conversation, in the sense of saying what she does as a way of cheering up the mood or generating enthusiasm, although she might also be aiming for such an effect. People sometimes say things that they merely hope are true as genuine contributions to a discussion. Such statements are typically meant to be genuine assertions, and not just as cheers 
or catcalls. We think such ways of speaking are best described as instances of bullshitting.

Relatedly, on the intended reading of the example, Julia is not trying to deceive either herself or Jack. Instead, Julia is trying to contribute to the conversation about the upcoming trip. She wants it to be part of that conversation that it is always dry in Chicago at that time of year. But, as we will argue, what characterizes her utterance is that, even though she is not indifferent to the truth-value of her assertion per se, she is not concerned with making either a true or a false contribution to the conversation.

\subsection{Bullshitting and Indifference toward Truth}

All these examples suggest that being indifferent toward the truth-value of what one says, in Frankfurt's sense, is not the only way of speaking with indifference toward truth. In this way they involve a more generalized sense of what Frankfurt thought of as the central characteristic of bullshitting. This is the main reason we think it is useful to describe speakers of this kind as engaged in bullshitting.

Yet some might worry that the category of bullshitting is too intangible for us to have firm judgments about, perhaps especially so when going beyond the kind of examples Frankfurt described. However, we think our project here is worth pursuing, even if it turns out that bullshitting is not a notion of which we always have a clear grasp. We take the kind of speech illustrated by the examples above to be an interesting phenomenon that it is worth theorizing about in its own right.

One of our goals is to show that the central piece of Frankfurt's analysisindifference toward truth and falsity - is a broader category than he originally supposed, and one that covers ways of speaking that his more narrow understanding of it is unable to capture. Even if one is skeptical about the project of precisely characterizing the notion of bullshitting per se, we think there is interest in bringing out some of the details of this broader kind of indifference toward truth and falsity.

In the next section we provide an account of this more general phenomenon which at the same time captures what was right about Frankfurt's original proposal. 


\section{Bullshitting and Inquiry}

\subsection{Inquiry and Subinquiries}

Despite cases like those above in which people show disregard for the truth, most of our talk exchanges are aimed at discovering or sharing truths. We are usually interested in telling other people true things, and in getting true information from others. Conversations, in this way, are typically aimed at pooling true information.

An influential and powerful account of this aspect of discourses is presented by the model of communication familiar from the work of Robert Stalnaker (1999a; 1984; 1999b; 2002). According to this model, discourse - that is, the purposeful exchange of information that characterizes most conversation-is ultimately aimed at reaching the goal of inquiry, the discovery of how things are, or what the actual world is like. More specifically, the ultimate goal of discourse is to incrementally contribute true information to a body of shared information, the common ground, with the aim of reaching a maximal information state that rules out all other possibilities than the actual world itself.

The Stalnakerian goal of inquiry represents the most general, overarching alethic goal that conversationalists might have. The Stalnakerian goal of inquiry is simply the goal of accumulating maximally specific true information. Yet our conversations are typically governed by much more modest goals. We are often engaged in inquiry with respect to one or more particular topics of conversation.

In recent work Craige Roberts $(2004 ; 2012)$ has developed an elegant way of understanding this more localized sense of inquiry. We think this framework can be usefully employed to shed light on central aspects of non-truth-oriented speech, in particular, bullshitting and its relation to lying. ${ }^{2}$ Below we provide a very rudimentary sketch of the main ideas that we want to appeal to. We want to stress up front, however, that in doing so, we are leaving out a number of central points, and we are allowing ourselves to keep our discussion at an informal level. ${ }^{3}$ We take it that it adds to the overall attraction of this framework that it allows for this kind of general implementation, and we think that ultimately, a more formal representation of what we argue here is fully within the scope of the kind of theory we sketch in this paper.

Roberts's central insight is that to approach the Stalnakerian goal of inquiry, QUDs.

2. Stokke (2016) gives an account of the difference between lying and misleading in terms of

3. It is increasingly recognized that QUDs form a central part of discourse contexts. For discussion, see, for example, Beaver and Clark (2008), Schoubye (2009), Potts (2010), Simons, Roberts, Tonhauser, and Beaver (2010), Schaffer and Szabó (2013), Schoubye and Stokke (2016), Stokke (2016). 
the discovery of how things are, "we must develop strategies for achieving this goal, and these strategies involve subinquiries" (Roberts 2012: 4). As suggested above, the Stalnakerian project of inquiry, that is, the general quest for true information about the state of the world, is typically not our immediate concern. Rather, we are more often committed to more local inquiries, such as discovering the truth about when the bus leaves, how cold it is outside, whether someone has done their homework, and so on.

The kind of subinquiries we typically pursue in ordinary discourse can be represented as questions like those in (1).

(1) a. When does the bus leave?

b. How cold is it outside?

c. Has John done his homework?

Along these lines, Roberts proposes to represent a subinquiry, understood as the topic of conversation, as a question that has been accepted as being under discussion. ${ }^{4}$ Instead of addressing what Roberts calls the Big Question, What is the world like?, head-on, we work piecemeal by addressing more specific questions. In other words, a conversation has as its immediate goals that of answering a set of QUDs.

Subinquiries are themselves typically approached through their own subsubinquiries. (To make things simple, we refrain from always making the distinction between subinquiries and sub-subinquiries explicit in what follows and simply speak of subinquiries.) To illustrate, consider Roberts's (2012: 16) example of a simplified discourse where only two individuals are relevant, Hilary and Robin, and only two kinds of foods, bagels and tofu. Given this context, to answer the question in (2), a safe strategy is to try to answer the subquestions in (2a) and (2b). To do so, one can set about answering their respective subquestions.

(2) Who ate what?

a. What did Hilary eat?

i. Did Hilary eat bagels?

ii. Did Hilary eat tofu?

b. What did Robin eat?

i. Did Robin eat bagels?

ii. Did Robin eat tofu?

4. Roberts (2012: 2) is explicit that the framework of questions under discussion is intended to capture the more traditional notion of a topic of conversation. 
In realistic cases discourse structure is not as simple as this. There will be more complex relations between subinquiries, or QUDs. We do not need to describe such relations for our purposes. ${ }^{5}$ It is enough to note that, first, contexts often contain multiple QUDs, and second, the QUDs in a context are often related to each other in such a way that, given the common ground and other features of the context, answering some is a means of at least partially answering others. For example, given the narrow context we are assuming, answering (2aii) is a way of partially answering (2a), and in turn, answering (2a) is a way of partially answering (2). Conversely, completely answering (2) is a way of completely answering all of the subquestions (2a), (2ai), (2aii), (2b), (2bi), and (2bii).

Discourse advances by participants making conversational moves. ${ }^{6}$ Briefly, there are two types of moves in a discourse. Participants typically either introduce a QUD, that is, a topic of conversation, or make a contribution toward answering a QUD. The former are setup moves and do not merely include explicitly asking a question. A QUD can be introduced in other ways than by explicitly asking it. For example, uttering ( $3 a$ ) is often a way of introducing the QUD in (3b).

(3) a. I'm trying to find Mary.

b. Where is Mary?

QUDs are resolved by participants making pay-off moves. These include assertions as well as other ways of contributing information to a discourse, such as conversational implicature. You can answer ( $3 b)$ either by asserting that Mary is in her office or by implicating that she is in her office. For example, in the right setting, you can implicate an answer to (3b) by asserting (4).

(4) I just saw her heading toward her office.

There are many ways of providing answers to QUDs.7 However, we will confine ourselves to assertion and (particularized) conversational implicature in what follows. As a general term, we use contributing that $p$ to mean either asserting that $p$ or conversationally implicating that $p$, and we use contribution accordingly to mean either an assertion or a conversational implicature.

We propose to use this way of looking at discourse structure to account for the phenomenon of bullshitting, that is, the ways in which we sometimes talk while being indifferent toward truth and falsity, and its relation to lying.

5. Roberts (2012: 15) defines a notion of contextual question-entailment, which is arguably a useful approximation of the structure of at least many ordinary types of discourse. See also Stokke (2016) for discussion.

6. See Roberts (2012: 4-5), Schoubye and Stokke (2016).

7. See Schoubye and Stokke (2016) for more details. 


\subsection{Bullshitting and Questions under Discussion}

Given that the goal is to advance toward truth, progress on subinquiries is made by contributing true answers to QUDs. A contribution that is a true answer to a QUD is a contribution to the progress of the discourse toward the goal of inquiry. Accordingly, in most cases, participants respond to QUDs by asserting things they believe to be true in order to contribute to the progress of the corresponding subinquiry.

Yet sometimes people try to subvert this project. Most obviously, this happens when someone is lying. Most lies are answers to QUDs. In such cases the liar asserts an answer she believes to be false and thereby steers the subinquiry away from the truth. In Section 5 we give an account of the difference between speaking truthfully, lying, and bullshitting. Here we want to spell out our account of the latter.

Rather than thinking of bullshitting narrowly in terms of indifference toward the truth-value of one's contributions, we propose seeing bullshitting as a way of subverting the pursuit of truth that is specifically characterized by indifference toward QUDs. The bullshitter makes contributions while not caring about their effect on particular subinquiries. More precisely, bullshitting is a matter of contributing to the conversation while being indifferent toward whether one's contributions are true or a false answers to QUDs. Bullshitting, on our account, is therefore relative to QUDs, or subinquiries.

We can now state the core of our proposal as follows:

Bullshitting (to be revised)

$A$ is bullshitting relative to a QUD $q$ if and only if $A$ contributes $p$ as an answer to $q$ and $A$ is not concerned that $p$ be a true or a false answer to $q$.

We will see later that we will need to refine this characterization in a particular way. But it is worth first developing this simpler idea.

On our view bullshitting centrally involves disregarding truth and falsity, as Frankfurt suggested. But while, for Frankfurt, bullshitting is marked by disregard for the truth-value of what is said, on our view, bullshitting is characterized in terms of disregard for the alethic effect of one's contributions on QUDs. As stipulated above, by a contribution we mean either an assertion or a conversational implicature.

Before showing how this account is an improvement on Frankfurt's we want to comment on an aspect of the latter, which has been taken up by some of his critics. In his well-known rejoinder to Frankfurt (2005), G. A. Cohen (2002) pointed out that one should distinguish between the activity of bullshitting and the 
product bullshit. As Cohen observed, Frankfurt provided an account of the former but not of the latter. We want to note up front that our account is, like Frankfurt's, an account of the activity of bullshitting. Since we are interested in giving an account of different ways in which speakers may be indifferent toward truth, and the relation between such speech and lying, we refrain from discussing the products of bullshitting in this paper. ${ }^{8}$

We now go on to show how our proposal captures both Frankfurtian indifference toward truth-value as well as the phenomenon of bullshitting while caring about truth we described earlier.

\subsection{Capturing Indifference toward Truth-Value}

The kind of bullshitting Frankfurt pointed to is represented by speakers who assert things without caring about the truth-value of what they are asserting. Consider, for example, Frankfurt's $4^{\text {th }}$ of July orator. For concreteness, suppose one of the orator's utterances is the one in (5).

(5) Under divine guidance our Founding Fathers created a new beginning for mankind.

The first thing to note is that the orator is making what we called a contribution to the conversation. That is, he is putting something forward for the common ground, and in particular, in uttering (5), the orator is making an assertion. In general, we assume that bullshitters are not engaged in non-assertoric speech acts like joking, irony, or play-acting. One piece of evidence for this is that bullshitting does not exempt one from the kind of commitment to what one says that characterizes ordinary cases of assertion. For example, even though the orator is bullshitting, he has no way of later denying responsibility for what he said by claiming that he was not speaking seriously. Correspondingly, the orator's statement can be met with challenges like 'Why do you think so?' Such challenges are not appropriate as responses to non-assertoric utterances like jokes or lines spoken during play-acting.

To be sure, there are situations involving non-assertoric utterances that are

8. The product Cohen is interested in is what he calls "nonsense," by which he means discourse that is "unclarifiable" (2002: 332). He distinguishes between "unclarity of a sentence itself" and "unclarity as to why a certain (possibly perfectly clear) sentence is uttered in a given context" (2002: 332). For Cohen, both these kinds of nonsense can be the product either of bullshitting or of not bullshitting. The QUD framework provides a way of cashing out these differences. An utterance may be nonsense, in Cohen's sense, if it is unclear how it contributes an answer to a particular QUD. This may be because it is unclear in itself, or because it is unclear how it relates to the relevant QUD. Yet utterances with either characteristic (or both) may be produced by someone who is bullshitting in our sense or by someone who is not. 
sometimes spoken of as involving bullshitting but which should nevertheless be regarded as of a fundamentally different kind. Consider, for example, Frankfurt's (2005: 34-37) discussion of 'bull sessions.' One kind of bull session is the familiar sort of informal conversation in which it is understood that people tell tall tales for amusement, for example, by saying things like, 'I caught a fish this big!' etc.

Frankfurt does not include utterances made as part of the kind of unserious conversation exemplified by bull sessions as instances of the phenomenon he is interested in. His motivation is that, as he says,

while the discussion may be intense and significant, it is in a certain respect not 'for real.' . . . What tends to go on in a bull session is that the participants try out various thoughts and attitudes ... without its being assumed that they are committed to what they say. . . (Frankfurt 2005: 35-37)

We take it that the natural thing to say about such cases is that the participants are not making contributions to the common ground of the conversation, in the relevant sense. ${ }^{9}$ In particular, they are not making assertions. Correspondingly, they are not committed to the things they say. For example, if someone later challenges the bragging fisherman with having been inaccurate about the size of his catch, the fisherman is in a position to respond with, 'Oh, come on, we were just fooling around!' or something similar. ${ }^{10}$ By contrast, as noted above, the $4^{\text {th }}$ of July orator's utterance of (5) incurs the typical commitment characteristic of assertion.

On our view what marks the orator's contribution as a case of bullshitting is that it is made without regard for its effect on the ongoing subinquiry, that is, without regard for whether it is a true or a false answer to the corresponding QUD.

Which QUD is the orator addressing? The answer depends on the details of the case. Frankfurt's remarks suggest that, as he is thinking of the case, part of the orator's indifference concerns 'what his audience thinks about the Founding

9. Ultimately, we think there are reasons to distinguish between a common ground that is maintained and relied on in unserious conversations and a common ground that is understood to be the record of serious discourse. Stokke (2013) spells out this kind of distinction between an 'official' common ground and one or more 'unofficial' common grounds that are used for keeping track of information, for example, during the performance of a play. The latter kind of unofficial common ground is arguably also operative during unserious conversation such as bull sessions. The notion of common ground in our characterization of bullshitting is intended to be the notion of the official common ground.

10. To be sure, we are not suggesting that in situations of this kind, one can simply say anything. There are other rules that apply, including norms of tact and perhaps other restrictions. 
Fathers, or about the role of the deity in our country's history' (Frankfurt 2005: 17). This might point to a question like (6a) or (6b) as the QUD that is being addressed by the orator's utterance of (5).

(6) a. How should we think of the Founding Fathers?

b. What is the role of the deity in our country's history?

As this suggests, it is not always easy to specify a particular QUD that is being addressed by a given utterance. But, as we explain below, we do not think this is a problem for our proposal.

As emphasized earlier, it is not an assumption of this view of discourse structure that QUDs are always explicitly asked. As Roberts says, "questions are often only implicit, inferred on the basis of other cues" (Roberts 2012: 8). The orator's speech is naturally seen as a case of this kind. In particular, it is natural to think that the occasion $-\mathrm{a} 4^{\text {th }}$ of July oration - provides obvious cues, to use Roberts's terminology, for inferring one or more QUDs for (5). These may be questions like the ones in (6).

What is characteristic of the orator is that he not concerned with providing true or false answers to such questions. In fact, the orator is most plausibly seen as disregarding whether he provides answers to QUDs at all. Most likely, he is concerned with presenting himself in a particular light. ${ }^{11}$ As Frankfurt suggests, the orator "wants [his audience] to think of him as a patriot, as someone who has deep thoughts and feelings about the origins and the mission of our country, ... and so on" (2005: 18). He is not concerned with contributing answers to subinquiries. On our view this is what marks the orator as bullshitting. While someone who makes an assertion almost always has some goal in mind in doing so, the phenomenon of bullshitting illustrates that the goal is not always to push a subinquiry closer to the truth.

The case of the $4^{\text {th }}$ of July orator illustrates the way in which our account subsumes Frankfurt's. Namely, if one is Frankfurt-bullshitting, one is also bullshitting on our view. If one asserts $p$ while being indifferent toward whether $p$ is true or false, one is asserting $p$ while being indifferent toward whether $p$ is a true or a false answer to any QUDs one is addressing with $p$. Yet as we will see next, the converse is not the case. In particular, our account allows that one may be bullshitting even if one is not indifferent toward the truth or falsity of what one is asserting.

11. Frankfurt (2005) argued that the bullshitter is characterized by a particular kind of intention to deceive, namely the intention to deceive about her own attitudes toward what she is asserting. Carson (2010) has argued that bullshitting does not necessarily involve intentions to deceive. In this paper we are concerned with the bullshitter's attitudes toward inquiry and subinquiries, and we refrain from discussion the issue of whether bullshitting requires intending to deceive. 


\subsection{Bullshitting while Caring about Truth}

As illustrated by the examples we cited in Section 2, there are different ways of being indifferent toward truth and falsity. We saw that one may be indifferent toward truth, in one sense, while not being indifferent toward the truth-value of one's assertions. We described such cases as cases of bullshitting while caring about truth. As we noted, this phenomenon appears to be quite widespread in that people often engage in talk that is, in some sense, characterized by indifference toward truth, while it would be wrong to say that they are indifferent toward whether what they say is true. Our proposal allows for such cases because it takes the mark of bullshitting to be indifference toward the effect of one's assertions on QUDs, and not simply indifference toward truth-value.

We considered two main ways in which speakers might care about the truthvalue of what they say. First, sometimes people take care to say true things, while being less concerned with which particular things they say. This kind of strategy was illustrated by the bullshitting student in the Careful Exam Taker case and by the filibustering of Cato the Younger. Neither is interested in asserting particular propositions because they care about the truth-value of those propositions. Rather, they merely have a general concern for asserting true propositions.

Carson imagines that the student is asked the following question in an exam for an applied ethics class:

Briefly describe the facts of the case of Dodge v. Ford and answer the following question: Was Henry Ford morally justified in his actions in this case? Defend your answer. (Carson 2010: 61)

But since the student is ignorant about the case, and is unable to construct a coherent argument, she gives a bullshit answer.

As the example is described, the student is nevertheless concerned with the truth or falsity of what she is asserting, since this is the way she thinks she is going to get partial credit. In particular, she is concerned with asserting things she believes to be true. For example, the student might assert things like those in $(7) \cdot{ }^{12}$

(7) a. There are many important ethical questions about the role of business in society.

b. The Ford Motor Corporation had different obligations in this case.

c. Utilitarians hold that corporations should promote the social good.

12. Adapted from Carson (2010: 61). 
However, the Careful Exam Taker is not concerned with whether her assertions are true or false answers to the QUD, that is, the exam question. ${ }^{13}$ Hence, our account explains the sense in which the student is bullshitting even though she is concerned with the truth of what she says. ${ }^{14}$ One can be indifferent toward truth in the sense of being indifferent toward the alethic effect of one's assertions on QUDs, while not being indifferent toward truth in the sense of not being indifferent toward the truth-value of what one is asserting.

In particular, the Careful Exam Taker is not concerned with giving true answers. She knows she is not able to answer the exam questions, and she is not trying to do so. Nor is she concerned with giving false answers. Those are not among the reasons why she says what she says. What characterizes her assertions is that considerations concerning whether her assertions are answers - true or false-are not among her reasons for saying what she does. She says what she does without concern for whether what she says are true or false answers to the QUDs.

The same points apply to the case of Cato the Younger. While he was concerned with truth in the sense of being careful to only say things he believed to be true, he was not concerned with whether his assertions were true or false answers to QUDs. As with the case of the $4^{\text {th }}$ of July orator, which questions Cato was addressing may not have been explicit. But, as we argued earlier, this does not prevent us from seeing his assertions as addressing QUDs.

\subsection{The Role of Evidence}

The other kind of bullshitting while caring about truth was exemplified by Julia's assertion of (8) in the Wishful Thinker example.

(8) This time of year, it's always dry in Chicago.

As in other cases, Julia's utterance is not a reply to a question that has been explicitly asked in the preceding context. But, again, we think that her assertion should nevertheless be seen as addressing a QUD. In particular, in this case, Julia's assertion is a response to Jack's utterance of, 'I'm really looking forward to

13. As Searle observed, "There are two kinds of questions: (a) real questions, (b) exam questions. In real questions $S$ wants to know (find out) the answer; in exam questions, $S$ wants to know if $H$ knows" (1969: 66). Accordingly, it may be objected that exam questions cannot be QUDs, in the same way that 'real' questions can be. However, we think it is likely that a plausible account of such cases can be given within the framework we have been suggesting. In particular, to treat an exam question as a QUD will probably ultimately require accepting that the teacher is, in some sense, pretending that the question is a 'real' one, but since, in these situations, everyone is aware of the pretense and everyone accepts it as necessary, it will make little difference for our purposes.

14. We acknowledge that the Careful Exam Taker only cares about the truth as a means to getting credit. But, of course, many perfectly legitimate (that is, non-bullshitting) assertors only care about the truth as a means to some further end. 
that Cubs game. I hope it won't rain.' It is therefore natural to see her assertion as addressing a corresponding question. For simplicity, we can assume that Julia's utterance addresses the question in (9).

(9) What are the chances of rain when we're going to see the Cubs game?

There are other ways one can try to identify the question addressed by Julia's utterance of (8). Yet what is important for our purposes is that she is addressing one or more QUDs, and the fact that she has a particular kind of attitude toward them.

As we noted, the central feature of this kind of example is that the speaker is not indifferent toward the truth-value of what she asserts. In asserting (8), Julia is not indifferent toward the truth-value of her assertion. Julia cares very much about whether (8) is true or not. She wants it to be true (or hopes or wishes that it is).

Correspondingly, there is arguably a sense in which Julia does care about whether her assertion is a true or a false answer to questions like (9). Namely, she hopes it is a true one. This highlights an important point about the proposal we are outlining, and one which Frankfurt arguably also overlooked. We have argued that the indifference that is characteristic of the kind of non-alethic talk we are interested in is indifference toward whether one's contributions push subinquiries toward truth or falsity. But as the example of Julia's assertion of (8) illustrates, this is not general enough, since Julia does care about her contribution being one that moves the subinquiry toward truth. Even so, there is a clear sense in which Julia is not showing the proper regard for inquiry. She is just saying what she does because she wants or hopes that it is true.

Instead, we propose that what makes Julia different from ordinary truthoriented speakers is that Julia is exhibiting a lack of concern for the role of evidence in inquiry. While she is, in the sense we have outlined, concerned with steering the subinquiry about the Chicago weather in the direction of truth, she is not concerned with doing so on the basis of evidence.

There are arguably many examples of this way of being indifferent toward inquiry. Scott Kimbrough gives an example of "an avid fan of conservative talk radio" who claims "that the French are an irrational and ungrateful people, and that liberals have an anti-Christmas agenda" (2006: 12-13). At least on one way of understanding this kind of example, the radio fan is concerned with giving true answers to the QUDs she is addressing, for example, what is the character of the French people, or the like. She cares about the truth of the things she says. Her failure, however, is that she does not care about evidence. She is not concerned with providing truths that she thinks are supported by evidence. Rather, she is just concerned with airing certain statements which she cares about. 
To be sure, there are versions of this kind of example where the speaker does care about evidence. In particular, sometimes people like the radio fan think they are giving answers to QUDs based on evidence, although their idea of what constitutes evidence is erroneous. In such cases, on our view, the speaker is not bullshitting. If one is concerned with providing true contributions that one takes to be supported by evidence, one is not bullshitting. One might be criticizable for other reasons, even epistemic ones. For instance, one might be criticizable for not having a proper conception of evidential support. Yet the kind of speaker we are imagining-like the Wishful Thinker-is someone who does not care about evidence at all.

As another illustration, we can imagine an exam taker who takes a guess on a question she is aware of not being able to answer. Like the Wishful Thinker and the radio fan, someone who tries to guess the right answer on an exam is not unconcerned with her answer being true or false. Like the Wishful Thinker, she hopes it is true. So she is not indifferent toward her contribution being a true or false answer. Rather, we think the right way to characterize the kind of indifference toward inquiry exhibited by this kind of speaker is as indifference toward basing her contribution on evidence. ${ }^{15}$

In light of this, the proposal we have set out, according to which bullshitting is a matter of contributing to a conversation without caring about providing true or false answers to QUDs, should be understood in a particular way. More precisely, what is lacking from this kind of talk is a concern for steering QUDs toward answers that one's evidence suggests to be true or that one's evidence suggests to be false. By contrast, what characterizes ordinary, truth-oriented speech is that speakers are concerned with steering subinquiries toward answers that their evidence suggests to be true. We can spell out this more refined version of our view as follows:

\section{Bullshitting (final version)}

$A$ is bullshitting relative to a QUD $q$ if and only if $A$ contributes $p$ as an answer to $q$ and $A$ is not concerned that $p$ be an answer to $q$ that her evidence suggests is true or that $p$ be an answer to $q$ that her evidence suggests is false.

15. The notion of basing one's contribution on evidence ultimately needs to be sharpened. In particular, it is not obvious that someone who has some evidence and bases a guess on that is not exhibiting indifference. One might want to distinguish between a contribution being sufficiently based on evidence and a contribution being informed by evidence, in light of such cases. We refrain from discussing the details of this issue here, since it is arguably a general problem concerning the relation between one's evidence and what it is reasonable to accept based on it. See Lehrer (2011) for some discussion. 
While the Wishful Thinker, the radio fan and the guessing exam taker we described above are not indifferent toward whether their assertions are a true or false answer to the questions they are addressing, their failure is that of not caring about whether their contribution reflects their evidence in the right way.

Further, the same holds of the bullshitters we considered earlier. The orator, the crafty student, and the filibustering Cato are all indifferent toward providing answers to QUDs based on evidence; indeed, they are all indifferent toward providing answers to QUDs, full stop. As before, this proposal captures the central idea behind Frankfurt's characterization of bullshitting as lack of concern for truth and falsity, while improving on it.

Finally, as we saw from Webber's (2013) example, another way of engaging in bullshitting while taking care to assert something one believes to be true is to do so with the object of implicating something one does not care about. This is another way of making a contribution, in our sense of either asserting or conversationally implicating, while being indifferent toward its effect on QUDs. For example, consider again the toothpaste advertisement featuring (10).

(10) Used by dentists!

The advertiser who asserts (10), so we assume, is deliberately asserting something her evidence suggests to be true. ${ }^{16}$ But she might thereby be implicating something else, such as that the toothpaste is good. In doing so, she is addressing a QUD like (11).

(11) Is this toothpaste good?

The assertion in (10) is made with the aim of implicating an answer to (11). Yet the advertiser is not concerned with whether this implicature constitutes an answer to (II) that she has evidence of being either true or false.

It might be said that in asserting that the toothpaste is used by dentists, the advertiser is also addressing a QUD like (12).

(12) Is this toothpaste used by dentists?

Moreover, with respect to this question, the advertiser is arguably concerned with providing a true answer (based on evidence). We agree with this. Indeed, we think there is a natural sense in which the advertiser, in this case, is bullshit-

16. It may not be the case that there is an individual who asserts (10) in a case like this. Instead, it might be a group such as a corporation or an advertising agency that is the agent making the assertion. We refrain from discussing group assertions, and by extension group bullshitting and group lying. We assume that our account applies, mutatis mutandis, to such cases. 
ting with respect to a subinquiry concerning the quality of the toothpaste, while not bullshitting with respect to a subinquiry concerning whether it is used by dentists. We take it to be a merit of our proposal that it allows for this kind of distinction.

In the next section we show how our account is able to capture some further ways of speaking with indifference toward truth and falsity. First, we consider the phenomenon of evasive bullshitting. Second, we turn to cases in which someone can be described as advancing inquiry by bullshitting.

\section{Evasion and Advancing Inquiry by Bullshitting}

\subsection{Evasive Bullshitting}

Carson points out that a common reason people engage in bullshitting is in order to evade certain topics of conversation:

Sometimes we are pressured to answer questions that we do not want to answer. When asked such questions, people often produce bullshit responses that do not directly answer the questions. (Carson 2010: 60)

However, it might be argued that our account implies that evasion is not a form of bullshitting. Typically, someone who is being evasive changes the subject. Given the framework we are assuming, to change the subject is to introduce a new QUD. For example, if one is asked the question in (13a), one might respond by uttering $(13 \mathrm{~b})$.

(13) a. Did you break that vase?

b. You know, I think Jackie's cold is getting better.

To do so is to evade the original QUD, that is, (13a), by introducing a new onein this case, the new QUD might be represented as (14).

(14) How is Jackie's cold?

Someone who evades a topic of conversation by introducing a new QUD might nevertheless be concerned with providing true or false answers to the new QUD. On our view, therefore, this type of evasion does not constitute bullshitting with respect to the new QUD. Still, as we explain below, while some evasion may turn out not to be bullshitting, our account nevertheless leaves room for a large amount of evasive bullshitting. 
First, not all evasion involves changing the subject. Sometimes there is no room for introducing alternative QUDs. This is illustrated by the Careful Exam Taker. The student, in this case, is naturally described as evading QUDs, that is, the exam questions. She realizes that she has nothing to contribute to these questions, and she therefore makes statements that, while she believes them, are not designed to be true or false answers to the exam questions.

Yet the exam situation is special, in that, while one can evade an exam question in the way the Careful Exam Taker does, one cannot change the topic. That is, one cannot propose to introduce a different QUD. In such cases evasion implies not addressing the only QUD that could be the topic of conversation. Hence, in such settings, evasion inevitably involves bullshitting.

Second, even if one does succeed in changing the topic, one might not care about providing true or false answers to the new QUD one has introduced. In such cases one is bullshitting, on our view. Imagine, for example, that a politician is asked the question in (15).

(15) Who is responsible for the deficit?

But because the politician does not want to discuss this question, she changes the topic and starts talking about climate change. She might say something like (16).

(16) Well, there are many issues we need to address. I think one of the most pressing ones concerns the urgent problems brought about by the impending rise of the sea levels.

She then goes on to expound at length on the causes of global warming, etc.

The politician here introduces a new QUD, for example, the one in (17).

(17) What are the most pressing problems we need to address?

Her assertion of (16) addresses (17) rather than (15). On our account, bullshitting is relative to QUDs. So the politician may or may not be bullshitting with respect to the new QUD, that is, (17), which she has introduced as a way of evading the original question in (15). She might be in earnest about the problems brought about by the impending rise of the sea levels being among the most pressing issues that need to be addressed. Accordingly, that the politician is evading the question she was asked does not necessarily make her a bullshitter, even though, to be sure, she may still be criticizable for evading the original question.

Conversely, it is not uncommon that someone evades a question by introducing a new topic, which they then go on to bullshit about. For example, the politician who responds to (15) with (16) might be bullshitting with respect to 
(17). That is, she might be bullshitting in asserting that the rising sea levels are among the most important things that should be addressed. Thereby she would be evading the original question in (15) by bullshitting about (17). As before, we take it to be an advantage of our account that it can capture such differences between cases.

A slightly more subtle type of situation is illustrated by an example that Carson gives:

In a televised presidential debate, a candidate is asked the following question: "I want to ask you about your criteria for nominating people to the US Supreme Court. Would you be willing to nominate anyone who supports the Roe v. Wade decision? Or, will you make opposition to abortion and Roe v. Wade a requirement for anyone you nominate?" The answer is that the candidate is not willing to nominate anyone who supports Roe v. Wade.... The candidate wishes that the question had not been asked and gives the following bullshit reply that completely fails to answer or address the question that was asked: "Look, there are lots of things to be taken into account when nominating someone for the Supreme Court. This isn't the only relevant consideration. I want someone with a good legal mind and judicial experience who supports my judicial philosophy of following the constitution as it is written." (Carson 2010: 60)

In this case the politician is not changing the topic in the same sense as someone who talks about climate change in response to a question about a budget deficit. Rather, it is natural to describe the politician in Carson's example as pretending to answer the question he was asked. On our view, this is a form of bullshitting because, while the politician is trying to appear as if he is addressing the original QUD, he is ignoring it. Hence, again, relativizing the kind of indifference toward inquiry that is characteristic of these kinds of speakers to QUDs allows us to account for how people sometimes engage in bullshitting evasion.

\subsection{Advancing Inquiry by Bullshitting}

Bullshitting may sometimes be used to advance inquiry. Specifically, bullshitting may sometimes be used to advance a particular subinquiry. For example, suppose that a prosecutor knows, through inadmissible evidence, that a suspect, Smith, is guilty. She is so concerned with getting Smith convicted that she is willing to say whatever she has to say in order to achieve that goal. The prosecutor might assert things like (18a) and (18b), even though she has no idea whether those things are true or false. 
(18) a.Smith had a clear motive.

b.Smith was at the scene of the crime.

In asserting such things, the prosecutor is showing disregard for contributing true or false answers to the corresponding questions, that is, (19a) and (19b).

(19) a. Did Smith have a motive?

b. Was Smith at the scene at the time of the crime?

The prosecutor wants to contribute answers to these questions, in particular, she wants to answer them with yes and yes. But she does not care whether those answers are true or false, nor does she care about whether they are supported by evidence. At the same time, she is concerned with getting to the true answer to $(20)$.

(20) Is Smith guilty?

She wants the yes-answer to this question to be accepted, and the reason she wants this is because she knows it is the true answer.

This case has some similarities with the cases of bullshitting while caring about truth we have looked at. While the prosecutor is bullshitting, she cares about the truth, in the sense that she wants to establish the truth that Smith is guilty. Yet unlike speakers like the Wishful Thinker or the Careful Exam Taker, the prosecutor does not care about the truth-value of what she says, that is things like (18a) and (18b). Hence, she is bullshitting with respect to questions like (19a) and (19b).

Is the prosecutor bullshitting with respect to (20)? Strictly speaking, our view does not take a stand on this issue unless the prosecutor's utterances are seen as contributing - that is, either asserting or conversationally implicating-answers to (20). Neither (18a) nor (18b) is an answer to (20), which admits of only one of two answers, yes or no, and correspondingly, uttering (18a) or (18b) is not a way of asserting an answer to (20). So, unless the prosecutor's utterances can be seen as contributing answers to (20) in some other way, our view remains neutral on whether she is bullshitting with respect to the question of whether Smith is guilty.

Perhaps some will want to argue that the prosecutor's assertions each conversationally implicate an answer to (20), that is, they implicate that Smith is guilty, perhaps via the Maxim of Relation, "Be Relevant" (Grice 1989: 27). Roughly, one might think that, in order to square the fact that the prosecutor asserts (18a) or ( $18 \mathrm{~b})$ with a presumption that she is obeying Relevance, one is required to 
assume that she wants to convey that Smith is guilty. Regardless of whether this proposal is ultimately plausible or not, we want to note that if the prosecutor's statements contribute answers to (20) in this way, our view implies that the prosecutor is not bullshitting with respect to this question, even though she is bullshitting with respect to questions like (19a) and (19b). The prosecutor is concerned with establishing the affirmative answer to (20), which is something she believes to be true on the basis of, albeit inadmissible, evidence. Indeed, she knows that Smith is guilty. Hence, she is not bullshitting with respect to (20).

In the next section we address the relation between bullshitting and lying. We will see that, although our account departs from Frankfurt's original view that the categories of bullshitting and lying are mutually exclusive, it still preserves the idea that most lies are not also instances of bullshitting. We argue that this is a further advantage of our account.

\section{Bullshitting and Lying}

\subsection{Bullshitting by Lying}

On Frankfurt's original analysis, bullshitting is sharply contrasted with lying. Frankfurt argued that, whereas the bullshitter is characterized by not caring about the truth or falsity of what she asserts, the liar is "inescapably concerned with truth-values" (2005: 51). Yet, as Frankfurt later came to recognize, it is natural to think that the two categories overlap in that speakers sometimes assert something they believe to be false while at the same time exhibiting the kind of indifference characteristic of bullshitting. People sometimes bullshit and lie at the same time. In his reply to Cohen (2002) Frankfurt (2002) acknowledged this overlap and moreover he argued that his account did not rule out such cases (see also Carson 2010: 61-62; Webber 2013: 655-656; Wreen 2013: 109).

The view we have argued for here agrees that the categories of lying and bullshitting are not mutually exclusive. On our view someone is bullshitting relative to a QUD if and only if she is indifferent toward whether her contribution is an answer that her evidence suggests to be true or suggests to be false. But, moreover, if someone with this sort of attitude asserts things they believe to be false, they are both lying and bullshitting.

However, we will argue later (in Section 5.3) that Frankfurt's (2002) own remarks on the intersection of lying and bullshitting admit of too much overlap. We will see that the QUD framework provides a view on which while lying and bullshitting are not mutually exclusive, most lies are not also instances of bullshitting. 


\subsection{Honest Folks and Real Liars}

In contrast to bullshitters, most speakers do care about the effects of their assertions on QUDs, and in particular, most speakers do care whether their assertions are true or false answers to QUDs. Yet there are different ways in which one can satisfy this condition, that is, there are different ways of avoiding bullshitting in the sense of being concerned with QUDs. It is useful to start by mapping out some of these before returning to the relation between lying and bullshitting.

First, and most obviously, there is the vast range of everyday situations in which people are interested in asserting true answers to QUDs because they are interested in contributing positively to the corresponding subinquiries. Call such speakers honest folks. For example, suppose Mitch asks Sarah what time it is. Sarah wants to help Mitch learn what time it is. So she looks at her watch, sees that it is 4 p.m. and tells Mitch that it is 4 p.m. Assertions like this are not lies, since they are cases in which the speaker believes what she is asserting. Nor are they cases of bullshitting, since they are cases in which the speaker wants her assertion to contribute an answer to the relevant QUD that her evidence suggests to be true. Honest folks neither lie nor bullshit.

Opposed to these are cases in which someone has the specific goal of adding a false proposition $p$ to the discourse, not because she is particularly interested in adding $p$ itself to the discourse but because she is interested in adding something false to the discourse. This is what Augustine called the "real" lie, that is, "the lie which is told purely for the pleasure of lying and deceiving ..." (1952: 87). Someone who tells you such a lie wants you to believe something false because it is false. Also, someone who tells you a lie so that she can subsequently discredit you when you repeat it wants you to believe something false because it is false. ${ }^{17}$

Real liars are not indifferent toward making true or false contributions to the topic of conversation, nor are they indifferent toward evidence. For example, if you ask someone for directions to the train station, they might give you an answer they know to be false simply because they take pleasure in making you go the wrong way. In this case, they are interested in giving you an answer that their evidence suggests to be false. Hence, Augustinian real liars are not bullshitters, on our account. They are not indifferent toward whether their assertions are evidence-based true or false answers to QUDs-they are concerned with their assertions being evidence-based false answers.

Similarly, suppose that before a big meeting with a foreign client, Bill asks Alice the question in (21).

(21) What's the name of their country's capital?

17. See also Ludlow (2013) for some real-life examples and discussion. 
Alice might give Bill a lying answer, not because she is particularly interested in what he believes about the name of the capital, but because she is planning to discredit him during the meeting by tricking him into blundering about the name. But it is still the case that Alice gives the answer she does because she cares about it being an answer that her evidence suggests is false. So she is not bullshitting, on our view.

\subsection{Most Lying is Not Bullshitting}

Finally, we want to return to the issue of the relation between bullshitting and lying. As we noted above, Frankfurt (2005) originally suggested that the categories are mutually exclusive. One reason for this was Frankfurt's observation that lying involves beliefs about what is true, whereas bullshitting does not require this kind of perspective. As he said,

It is impossible for someone to lie unless he thinks he knows the truth. Producing bullshit requires no such conviction. A person who lies is thereby responding to the truth, and he is to that extent respectful of it. (Frankfurt 2005: 55-56)

This was also the reason Frankfurt thought that "bullshit is a greater enemy of the truth than lies are" (Frankfurt 2005: 61).

Subsequently Frankfurt (2002) nevertheless came to recognize that the two categories overlap in the sense that someone might be telling lies while still being indifferent in the way relevant for bullshitting:

My presumption is that advertisers generally decide what they are going to say in their advertisements without caring what the truth is. Therefore, what they say in their advertisements is bullshit. Of course, they may also happen to know, or they may happen to subsequently discover, disadvantageous truths about their product. In that case what they choose to convey is something that they know to be false, and so they end up not merely bullshitting but telling lies as well. (Frankfurt 2002: 341)

Our view agrees that lying and bullshitting are not mutually exclusive. For example, suppose the $4^{\text {th }}$ of July orator, during his speech, tells the story about George Washington cutting down a cherry tree as a child, even though he has considered the evidence for the authenticity of the story and believes it to be false. We think that, since the orator in this case is asserting something he believes to be false, he is lying. Moreover, the orator's belief that what he says is false is based on evidence. But this does not mean that he is not also bullshitting. 
Even though he asserts something his evidence suggests to be false, this does not mean that he makes his assertion with a concern for providing an evidencebased answer to a subinquiry. In line with how we described the orator earlier, his goal in telling the story might not be to provide an answer to a QUD, but rather to present himself in a particular way. If so, he is lying while being indifferent toward whether his assertion is a contribution to a QUD, and hence he is both lying and bullshitting.

On the other hand, we think our account should be able to limit the amount of overlap between bullshitting and lying, and thereby preserve the core of Frankfurt's (2005) original idea that there is a significant and interesting difference between these two kinds of non-alethic modes of speech. As we will argue, there is a difference between most liars and liars who are moreover exhibiting the kind of indifference that we identify as at the core of the phenomenon of bullshitting.

Frankfurt's own remarks on the overlap between lying and bullshitting arguably do not suffice for capturing this difference. As we saw above, according to the way Frankfurt thinks of the bullshitting advertisers, they "decide what they are going to say in their advertisements without caring what the truth is" (Frankfurt 2002: 341). Yet this characterization is arguably insufficient to distinguish them from many liars, in fact it is arguably insufficient to distinguish them from most liars.

Frankfurt points out that most liars are not Augustinian real liars:

Everyone lies from time to time, but there are very few people to whom it would often (or even ever) occur to lie exclusively from a love of falsity or of deception. (Frankfurt 2005: 59)

Arguably, most cases of lying are cases in which someone has the goal of asserting something not because it is false, but because asserting that particular thing serves their purposes, regardless of its truth-value. Consider, for example, the following story.

\section{Umbrella}

Louise wants to sell Tom an umbrella. She knows that Tom is going to Chicago. Even though Louise believes the opposite, she invents the story that it is always raining in Chicago at that time of year, and she tells Tom that in order to make him buy the umbrella.

Unlike the Augustinian real liar, Louise is not telling Tom the lie because it is false, but because she wants to tell him that story, in order to sell him the umbrella. In particular, Louise's goals would have been satisfied, even if she believed 
the weather in Chicago to be the way she says it is. In that case she could just have told him what she believed. We call liars like Louise ordinary liars.

Given that the kind of lie Louise tells is the most common one, it would be desirable not to count such ordinary liars as also bullshitting. However, Frankfurt's suggestion about the bullshitting advertisers applies to ordinary liars as well. It is plausible to describe Louise as deciding what she is going to say without caring what the truth is. In particular, Louise decides to tell Tom that it's always raining in Chicago at that time of year with the aim of selling him the umbrella but without caring whether it is true or false. So, given Frankfurt's (2002) remarks about the advertisers, ordinary liars like Louise will be seen as bullshitters as well.

This result is an unwelcome one, since not only does it mean that most lying is also bullshitting, but it also appears to obscure a genuine difference between speakers like Louise and speakers like the orator. In particular, there is a kind of indifference that is characteristic of the latter kind of speaker which is not characteristic of ordinary liars like Louise. It would be of interest if we can find a way of describing this kind of indifference and thereby distinguish Louise from bullshitters. As we argue below, our account offers a way of doing so.

We agree that there is a sense in which Louise is indifferent toward whether her assertion is suggested by her evidence to be a true or a false answer to the QUD - that is, What is the weather like in Chicago this time of year? The sense in which Louise is indifferent toward how her assertion relates to this question is the sense in which honest folks and Augustinian real liars are not indifferent to QUDs. Unlike either of these, Louise's opinion of the truth-value of the story does not play a role in why she tells it. Indeed, this is the sense in which ordinary liars satisfy Frankfurt's (2002) characterization of the bullshitting advertisers as deciding what they are going to say without caring about what the truth is.

However, there is also a sense in which Louise does care about whether her assertion is suggested by her evidence to be a true or a false answer. One way to bring this out is by noting the familiar type of ambiguity exhibited by the attribution in (22). (For simplicity, we leave out the involvement of evidence here.)

(22) Louise wants to answer the QUD with something she believes to be false.

On one reading (22) is false. This is the reading on which Louise is being said to be an Augustinian real liar, that is, the reading on which Louise's goal is to assert something false because it is false. Yet on another reading, the attribution is true. This is the reading on which Louise is being said to have the goal of asserting a particular proposition $p$, while believing that $p$ is false.

It is true of both the real liar and of Louise that they want to contribute to the 
relevant subinquiry with something they believe to be false. There are different reasons why they want to do so. But, for both, what they hope to achieve is for the relevant subinquiry to move away from the truth. Hence, in that sense, neither is indifferent toward whether their assertion is a true or a false answer to the QUD. Both are concerned with giving false answers.

To be sure, the real liar and Louise differ when one considers what they would have wanted, had their beliefs been different. In particular, if the real liar had believed the proposition she asserts to be true, her goal would not be served by asserting that proposition, but would be served by asserting its negation. By contrast, Louise could have asserted the same thing, even if she believed it to be true. But this does not mean that they are not both actually concerned with asserting something false.

It is important to emphasize that the fact that we can distinguish between these two kinds of liars by appealing to different readings of ascriptions like (22) is not an artifact of our account. The analogous claims apply to ascriptions like (23).

(23) Sue wants to tell Bob something she believes to be false. Who is responsible for the deficit?

Like (22), (23) has two readings. More generally, the difference between the real liar and ordinary liars can be seen as an instance of the familiar phenomenon of de re versus de dicto attitude ascriptions. Suppose Anna wants to vote for Clinton. Moreover, Anna knows that Clinton wears pantsuits. So it is true that Anna wants to vote for the candidate who wears pantsuits. But of course, the latter statement can be read two ways. On one reading it ascribes to Anna the desire to vote for Clinton, who happens to wear pantsuits. On the other it ascribes to Anna the desire to vote for the candidate who wears pantsuits, who happens to be Clinton. This is the same kind of ambiguity as we are highlighting with (22) and (23).

In other words, on our view, ordinary liars like Louise are not bullshitting. It is true that ordinary liars may at first sight look very much like the orator, and vice versa. However, the difference is that the orator is not concerned with contributing to a subinquiry. The orator, as we described him earlier, is interested in presenting himself in a particular light. Neither reading of the relevant version of (22) is true of the orator.

Crucially, this characterization of the orator, on our view, holds even in the case where he is lying. When the orator tells the anecdote about Washington, even though he believes it to be false, he is not doing so because he wants to contribute an answer, true or false, to a QUD like Did George Washington chop down a cherry tree as a child? Rather, he tells the story for another reason. Most likely, he 
wants to present himself as an admirer of Washington, or the like. Hence, when the orator is lying, he is nevertheless also bullshitting, on our view. That is, even though he is lying, he is exhibiting a distinctive kind of indifference toward the state of the discourse. On the other hand, as we have argued, ordinary liars are not indifferent in this way.

Consequently, ordinary liars, like the Augustinian real liar, are not bullshitting on our view. The ordinary liar is concerned with truth-values, albeit in another sense than the Augustinian real liar is. So, since neither real liars nor ordinary liars are bullshitters, on our account, most lies are not instances of bullshitting.

\section{Conclusion}

Bullshitting is asserting with indifference toward whether one's assertion is an answer to a QUD that one's evidence suggests to be true or a false. Doing so does not rule out caring about the truth-value of one's assertion. Hence, while Frankfurt was right that bullshitting involves a disregard for truth and falsity, bullshitting is not just a matter of being indifferent toward the truth-value of one's assertions. Instead, bullshitting involves disregard for providing a true or false contribution to an ongoing subinquiry. Rather than being marked by indifference toward the truth of what one says, bullshitting is a mode of speech that is marked by indifference toward the project of furthering inquiry by making progress on more specific subinquiries.

Bullshitting, on this view, is consistent with lying, although most lies are not also instances of bullshitting. Lying and bullshitting are both ways of subverting the process of sharing true information, and hence such modes of discourse are disruptive to our ways of acquiring knowledge from the testimony of others. While the account presented here has not been concerned with the epistemology of testimony, relating lying and bullshitting to the project of inquiry highlights the fact that, in terms of our ways of sharing information with each other, we are not simply concerned with the truth of individual propositions. Correspondingly, we do not value epistemic states simply based on the proportion of true to false beliefs. Truthfulness is a value, at least in part, because we care about making progress on particular subinquiries.

Our account of bullshitting makes sense of Frankfurt's claim that bullshitting is a particularly dangerous 'enemy of truth' (Frankfurt 2005: 61). While lying on our view, and on Frankfurt's, is a matter of making a particular false assertion, bullshitting marks a wider sense of disregard for truth. Namely, bullshitting is a mode of speech characterized by indifference toward the progress of the project of inquiry as such. 


\section{Acknowledgements}

A previous version of this paper was presented at the Johannes Gutenberg University Mainz, September 2014. We are grateful to the audiences on this occasion for helpful discussion, and in particular, to James Mahon, Jennifer Lackey, and Jörg Meibauer. We are also indebted to Eliot Michaelson, Kay Mathiesen, Roy Sorensen, Tom Carson, and two anonymous referees for Ergo for useful comments and suggestions.

\section{References}

Augustine (1952). Lying. In Roy Joseph Deferari (Ed.), Treatises on Various Subjects (53120). Catholic University of America.

Beaver, David and Brady Z. Clark (2008). Sense and Sensitivity: How Focus Determines Meaning. Wiley Blackwell. https://doi.org/10.1002/9781444304176

Black, Max (1983). The Prevalence of Humbug. In The Prevalence of Humbug and Other Essays (115-146). Cornell University Press.

Carson, Thomas (2006). The Definition of Lying. Noûs, 4o(2), 284-306. https://doi. org/10.1111/j.0029-4624.2006.00610.x

Carson, Thomas (2010). Lying and Deception. Oxford University Press. https://doi. org/10.1093/acprof:oso/9780199577415.001.0001

Carson, Thomas (2016). Frankfurt and Cohen on Bullshit, Bullshitting, Deception, Lying, and Concern with the Truth of What One Says. Pragmatics \& Cognition, 23(1), 54-68. https://doi.org/10.1075/pc.23.1.03car

Cohen, Gerald A. (2002). Deeper into Bullshit. In Sarah Buss and Lee Overton (Eds.), Contours of Agency: Essays on Themes from Harry Frankfurt (321-339). MIT Press.

Dynel, Marta (2011). A Web of Deceit: A Neo-Gricean View on Types of Verbal Deception. International Review of Pragmatics, 3, 139-67.https://doi.org/10.1163/187731011X597497

Fallis, Don (2009). What is Lying? Journal of Philosophy, 106(1), 29-56.

Fallis, Don (2015). Frankfurt Wasn't Bullshitting! Southwest Philosophical Studies, 37, 1120.

Frankfurt, Harry (1988). The Importance of What We Care About. Cambridge University Press. https://doi.org/10.1017/CBO9780511818172

Frankfurt, Harry (2002). Reply to G. A. Cohen. In Sarah Buss and Lee Overton (Eds.), Contours of Agency: Essays on Themes from Harry Frankfurt (340-344). MIT Press.

Frankfurt, Harry (2005). On Bullshit. Princeton University Press.

Grice, H. Paul (1989). Studies in the Way of Words. Harvard University Press.

Kimbrough, Scott (2006). On Letting It Slide. In Gary L. Hardcastle and George A. Resich (Eds.), Bullshit and Philosophy (3-18). Open Court.

Lehrer, Keith (2011). Evidentialism and the Paradox of Parity. In Trent Dougherty (Ed.), Evidentialism and its Discontents (55-68). Oxford University Press. https://doi. org/10.1093/acprof:oso/9780199563500.003.0004

Ludlow, Peter (2013, June 14). The Real War on Reality. New York Times. Retrieved from http://opinionator.blogs.nytimes.com/2013/o6/14/the-real-war-on-reality 
Potts, Christopher (2010). On the Negativity of Negation. Proceedings of SALT 20. https:// doi.org/10.3765/salt.v20i0.2565

Roberts, Craige (2004). Context in Dynamic Interpretation. In Laurence R. Horn and Gregory Ward (Eds.), The Handbook of Pragmatics (197-220). Blackwell.

Roberts, Craige (2012). Information Structure in Discourse: Toward an Integrated Formal Theory of Pragmatics. Semantics \& Pragmatics, 5, 1-69. https://doi.org/10.3765/sp.5.6

Saul, Jennifer Mather (2012). Lying, Misleading, and What Is Said: An Exploration in Philosophy of Language and in Ethics. Oxford University Press. https://doi.org/10.1093/acprof :oso/9780199603688.001.0001

Schaffer, Jonathan and Zoltán Gendler Szabó (2013). Epistemic Comparativism: A Contextualist Semantics for Knowledge Ascriptions. Philosophical Studies, 168(2), 1-53.

Schoubye, Anders J. (2009). Descriptions, Truth-Value Intuitions, and Questions. Linguistics and Philosophy, 32(6), 583-617. https://doi.org/10.1007/s10988-010-9069-y

Schoubye, Anders and Andreas Stokke (2016). What Is Said? Noûs, 5o(4), 759-793. https:// doi.org/10.1111/nous.12133

Searle, John (1969). Speech Acts: An Essay in the Philosophy of Language. Oxford University Press. https://doi.org/10.1017/cbo9781139173438

Simons, Mandy, C. Roberts, J. Tonhauser, and D. Beaver (2010). What Projects and Why. Proceedings of SALT 20, 309-327. https://doi.org/10.3765/salt.v20i0.2584

Sorensen, Roy (2007). Bald-Faced Lies! Lying Without the Intent to Deceive. Pacific Philosophical Quarterly, 88(2), 251-264. https://doi.org/10.1111/j.1468-0114.2007.00290.x

Sorensen, Roy (2011). What Lies Behind Misspeaking. American Philosophical Quarterly, 48(4), 399-409.

Stalnaker, Robert (1984). Inquiry. MIT Press.

Stalnaker, Robert (1999a). Assertion. In Context and Content (78-95). Oxford University Press.

Stalnaker, Robert (1999b). On the Representation of Context. In Context and Content (96114). Oxford University Press. https://doi.org/10.1093/0198237073.003.0006

Stalnaker, Robert (2002). Common Ground. Linguistics and Philosophy, 25(5), 701-721. https://doi.org/10.1023/A:1020867916902

Stokke, Andreas (2013). Lying and Asserting. Journal of Philosophy, 110(1), 33-6o. https:// doi.org/10.5840/jphil2013110144

Stokke, Andreas (2016). Lying and Misleading in Discourse. Philosophical Review, 125(1), 83-134. https://doi.org/10.1215/00318108-3321731

Webber, Jonathan (2013). Liar! Analysis, 73(4), 651-659. https://doi.org/10.1093/analys/ ant081

Wreen, Michael (2013). A P.S. on B.S.: Some Remarks on Humbug and Bullshit. Metaphilosophy, 44(1-2), 105-15. https://doi.org/10.1111/meta.12021 